\title{
Observations of a quasi shear-free lacustrine convective boundary layer: Stratification and its implications on turbulence
}

\author{
Tobias Jonas, ${ }^{1,2}$ Adolf Stips, ${ }^{3}$ Werner Eugster, ${ }^{3}$ and Alfred Wüest ${ }^{5}$ \\ Received 16 April 2002; accepted 13 June 2003; published 21 October 2003.
}

[1] Convection due to surface cooling has been investigated in the surface boundary layer of a small lake under near-ideal conditions undisturbed by wind, large-scale currents, and differential cooling. Successive temperature microstructure profiles revealed a stable stratification in the lower bulk of the convective boundary layer despite strong cooling over the entire layer. Lateral heat fluxes as well as heat exchange with the thermocline could be excluded as driving mechanism of the observed stratification. Acoustic Doppler current profiler (ADCP) measurements indicated an asymmetric pattern of vertical velocities: strong downward plumes were observed upon a background of slow upflow. We suggest that this asymmetry allows cold water from the super-adiabatic surface layer to intrude at the base of the convective layer, thus causing the observed stratification. This in particular involves downward plumes that feature a relatively low entrainment rate in the center bulk of the convective layer. Corresponding large-eddy simulation studies, as well as thermistor string and ADCP data, were found consistent with this scenario. The dissipation rate of turbulent kinetic energy (TKE) was estimated on the basis of the temperature microstructure profiles and from the ADCP data. Mean dissipation rates of only about $20 \%$ of the surface buoyancy flux were typically identified. This finding is attributed to respectively low buoyant production rates of TKE, attenuated by strong convective plumes penetrating through the stable stratification in the lower bulk of the convective layer into the thermocline. INDEX TERMS: 4568 Oceanography: Physical: Turbulence, diffusion, and mixing processes; 4524 Oceanography: Physical: Fine structure and microstructure; 4572 Oceanography: Physical: Upper ocean processes; 4239 Oceanography: General: Limnology; KEYWORDS: convection, temperature microstructure, ADCP, stratification, turbulent kinetic energy, convective boundary layer

Citation: Jonas, T., A. Stips, W. Eugster, and A. Wüest, Observations of a quasi shear-free lacustrine convective boundary layer: Stratification and its implications on turbulence, J. Geophys. Res., 108(C10), 3328, doi:10.1029/2002JC001440, 2003.

\section{Introduction}

[2] Convection is an important source of vertical mixing in natural waters, governing to a large extent the physical, chemical, and biological dynamics. This particularly applies to water bodies with little wind exposure. Here we focus on convection in the surface layer, induced by heat loss to the atmosphere in the absence of interfering wind mixing and lateral density gradients.

[3] Shay and Gregg [1984, 1986] were one of the first to address an experimental study on convective mixing in the oceanic surface boundary layer. Dissipation rates $\varepsilon$ of

\footnotetext{
${ }^{1}$ Swiss Federal Institute of Environmental Science and Technology, Dübendorf, Switzerland.

${ }^{2}$ Now at Alpine Environment Section, Swiss Federal Institute for Snow and Avalanche Research, Davos Dorf, Switzerland. Italy.

${ }^{3}$ Inland and Marine Waters Unit, CEC Joint Research Centre, Ispra,

${ }^{4}$ Geographical Institute, University of Bern, Bern, Switzerland.

${ }^{5}$ Swiss Federal Institute of Environmental Science and Technology, Kastanienbaum, Switzerland.
}

Copyright 2003 by the American Geophysical Union. 0148-0227/03/2002JC001440 turbulent kinetic energy (TKE) in the interior of the boundary layer $\left(-L_{M}<z<D\right)$ were found proportional to the surface buoyancy flux $J_{b}^{0}$ ( $L_{M}$ is the Monin-Obukhov length, $z$ is the water depth, and $D$ is the mixed layer depth). Accordingly scaled dissipation rates $\varepsilon / J_{b}^{0}$ averaged out at around 0.61 to 0.72 , where 0.5 is the expected value for nonpenetrative, steady state convection in an ideal mixed layer [e.g., Deardorff, 1970]. The observed vertical structure of $\varepsilon / J_{b}^{0}$ resembled corresponding profiles from atmospheric boundary layers [Kaimal et al., 1976; Guillemet et al., 1983]. However, the similarity between oceanic and atmospheric convective boundary layers (CBL) ceases to apply toward the surface, where differences have been attributed chiefly to phenomena related to surface waves on the ocean [Anis and Moum, 1995; Noh and Kim, 1999].

[4] Lombardo and Gregg [1989] separately considered six stages within the diurnal cycle of convective mixing in the night and restratification during the day. As a depth scale, they introduced the temporary mixing layer depth $D^{*}$ [see also Brainerd and Gregg, 1995] replacing the (remnant) mixed layer depth D. Anis and Moum [1992] reported sublayers within the CBL. Beneath a presumed skin surface layer of a few millimeters thickness [e.g., Soloviev and 
Schlüssel, 1996], a super-adiabatic layer was identified. Below, they found a mixed layer followed by the thermocline as the entrainment zone. Imberger [1985], in contrast, observed a 'concave trend' in temperature profiles of a lake's CBL: instable stratification at the surface gradually evolving with depth into stable stratification at the base of the CBL. Similar characteristics of the CBL were also observed by Brubaker [1987], Anis and Moum [1994], and Brainerd and Gregg [1997].

[5] A few authors have explicitly analyzed the excess stratification within the turbulent $\mathrm{CBL}$, with different explanations; due to (1) enhanced entrainment from the adjacent thermocline driven by shear stress [Mahrt and André, 1983] (analyzing Deardorff and Willis' [1982] experiments), (2) gravitational relaxation of lateral into vertical density gradients [Brainerd and Gregg, 1997], and (3) tilted paths of the convective flow in the presence of lateral density gradients [Haine and Marshall, 1998]. However, laboratory experiments by Deardorff et al. [1969] indicate the existence of excess density gradients within convectively mixing layers even in the absence of the three above listed driving phenomena. Moreover, in these experiments the characteristic CBL stratification evolved clearly before convective thermals became penetrative, driving enhanced heat exchange with the thermocline.

[6] In this study we present successive temperature microstructure profiles over four diurnal cycles during convective conditions at night. The data reveal a stable stratification in the lower bulk of the CBL despite strong cooling over the entire layer. We consider a steady state convective regime that allows the generation of the observed stratification pattern due to internal processes, but neither due to interfacial nor to laterally advective processes. Moreover, estimates of the buoyant production and the dissipation of TKE enable an analysis of the implications of the observed stratification on turbulence.

[7] A small wind-protected and simply shaped lake was selected in order to investigate cooling-induced convective turbulence undisturbed by wind or other large-scale effects. A temperature microstructure profiler (TMP) was deployed to evaluate the dissipation rate of TKE. Additionally, a high-resolution acoustic Doppler current profiler (ADCP) was employed, to a) analyze the current pattern in the convective layer, and b) to verify the estimates of the TKE dissipation rate by a second independent method.

[8] We first evaluate the surface heat flux using three different data sets: consecutive temperature profiles, thermistor string data, and meteorological data (section 3.1). Then, the diurnal stratification pattern is analyzed by means of consecutive temperature profiles and thermistor string data (section 3.2). ADCP data are interpreted to gain insight into the three-dimensional flow structure (section 3.3). Finally, the estimations of $\varepsilon$ on the basis of both the TMP and the ADCP data are presented and compared in section 3.4. The discussion (section 4) focuses on the following two aspects: A regime is considered which allows maintenance of the stable stratification in the lower bulk of the CBL (section 4.1), and observations of atypically low dissipation rates are discussed by means of the TKE balance (section 4.2).
Table 1. Notation

\begin{tabular}{|c|c|c|}
\hline Property & Unit & Description \\
\hline$c_{B}$ & & Batchelor constant \\
\hline$D$ & $\mathrm{~m}$ & remnant mixed layer depth (positive) \\
\hline$D^{*}$ & $\mathrm{~m}$ & mixing layer depth (positive) \\
\hline$F$ & $\mathrm{~W} \mathrm{~kg}^{-1}$ & vertical divergence of TKE transport \\
\hline$g$ & $\mathrm{~m} \mathrm{~s}^{-2}$ & gravitational acceleration \\
\hline$H$ & $\mathrm{~W} \mathrm{~m}^{-2}$ & surface heat flux \\
\hline$J_{b}$ & $\mathrm{~W} \mathrm{~kg}^{-1}$ & buoyancy flux \\
\hline$J_{b}{ }^{0}$ & $\mathrm{~W} \mathrm{~kg}^{-1}$ & surface buoyancy flux, $J_{b}^{0}=J_{b}(z=0)$ \\
\hline$k$ & $\mathrm{cpm}$ & Wave number \\
\hline$L_{M}$ & $\mathrm{~m}$ & Monin-Obukhov length \\
\hline$N$ & $\mathrm{~s}^{-1}$ & Brunt-Väisälä frequency \\
\hline$p^{\prime}$ & $\mathrm{kg} \mathrm{m}^{-1} \mathrm{~s}^{-2}$ & turbulent fluctuation of pressure \\
\hline$Q_{T}$ & $\mathrm{~K} \mathrm{~m} \mathrm{~s}^{-1}$ & vertical turbulent temperature flux \\
\hline $\operatorname{Re}_{b}$ & & buoyancy Reynolds number \\
\hline$T$ & ${ }^{\circ} \mathrm{C}$ & water temperature \\
\hline$T^{\prime}$ & $\mathrm{K}$ & turbulent fluctuation of $\mathrm{T}$ \\
\hline$t$ & $\mathrm{~s}$ & time \\
\hline TKE & $\mathrm{m}^{2} \mathrm{~s}^{-2}$ & turbulent kinetic energy \\
\hline$u_{5 m}$ & $\mathrm{~m} \mathrm{~s}^{-1}$ & wind speed $5 \mathrm{~m}$ above ground \\
\hline$\overline{\bar{u}}$ & $\mathrm{~m} \mathrm{~s}^{-1}$ & average advection velocity \\
\hline$w^{\prime}$ & $\mathrm{m} \mathrm{s}^{-1}$ & turbulent fluctuation of vertical velocity \\
\hline$z$ & $\mathrm{~m}$ & water depth (positive downward) \\
\hline$\alpha$ & $\mathrm{K}^{-1}$ & thermal expansivity of water \\
\hline$\alpha_{K}$ & & three-dimensional Kolmogorov constant \\
\hline$x$ & $\mathrm{~K}^{2} \mathrm{~s}^{-1}$ & dissipation rate of $\mathrm{T}$ variance \\
\hline$\varepsilon$ & $\mathrm{W} \mathrm{kg}^{-1}$ & dissipation rate of TKE \\
\hline$\varepsilon_{A D C P}$ & $\mathrm{~W} \mathrm{~kg}^{-1}$ & $\varepsilon$ from inertial dissipation method \\
\hline$\varepsilon_{E A W A G}$ & $\mathrm{~W} \mathrm{~kg}^{-1}$ & $\varepsilon$ from EAWAG fitting method \\
\hline & $\mathrm{W} \mathrm{kg}^{-1}$ & $\varepsilon$ from maximum likelihood fittings \\
\hline$\Phi_{l d}^{B}$ & $\mathrm{~K}^{2} \mathrm{cpm}^{-1}$ & one-dimensional Batchelor spectrum \\
\hline$\Phi^{K}$ & $\mathrm{~m}^{2} \mathrm{~s}^{-2} \mathrm{~Hz}^{-1}$ & three-dimensional velocity power spectrum \\
\hline$\Phi_{1}^{K}$ & $\mathrm{~m}^{2} \mathrm{~s}^{-2} \mathrm{~Hz}^{-1}$ & along-stream contribution to $\Phi^{K}$ \\
\hline$\Phi_{2}^{K}$ & $\mathrm{~m}^{2} \mathrm{~s}^{-2} \mathrm{~Hz}^{-1}$ & cross-stream contribution to $\Phi^{K}$ \\
\hline$\kappa_{T}$ & $\mathrm{~m}^{2} \mathrm{~s}^{-1}$ & molecular diffusivity of heat in water \\
\hline$v$ & $\mathrm{~m}^{2} \mathrm{~s}^{-1}$ & kinematic viscosity of water \\
\hline$\rho$ & $\mathrm{kg} \mathrm{m}^{-3}$ & density of water \\
\hline 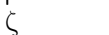 & & dimensionless depth, $\zeta=z / D^{*}$ \\
\hline
\end{tabular}

[9] The notation used in the following is specified in Table 1.

\section{Data Acquisition and Methods}

\subsection{Site and Experimental Setup}

[10] For our study we chose Soppensee, a small lake on the Swiss Plateau. This lake has a maximum depth of $27 \mathrm{~m}$, a mean depth of $12 \mathrm{~m}$, and an oval surface of approximately 800 by $400 \mathrm{~m}$ (Figure 1). It is wind-protected by surrounding bands of trees and does neither feature a surface inflow nor an outflow during autumn. Moreover, differential cooling [Monismith et al., 1990; Sturman et al., 1999; Fer et al., 2002] at the edges was not expected to have a significant impact on the lake's stratification, as zones shallower than the convective layer depth $(D \approx 6 \mathrm{~m})$ are scarce because of the lake's bottom topography (Figure 1).

[11] A SeaBird (SBE-Electronics, Washington, USA) temperature microstructure profiler was installed in a cable-constrained uprising profiling mode (Figure 2) to ensure that the complete surface layer was sampled. The profiler was released at an upward speed of $0.08 \mathrm{~m} \mathrm{~s}^{-1}$. To minimize self-induced turbulence, the device was dragged back down to its starting position at the same slow speed. Therefore $15 \mathrm{~min}$ were sufficient downtime between two successive casts. The profiler was equipped with two FP07 thermistors (Thermometrics, New Jersey, USA). Including 


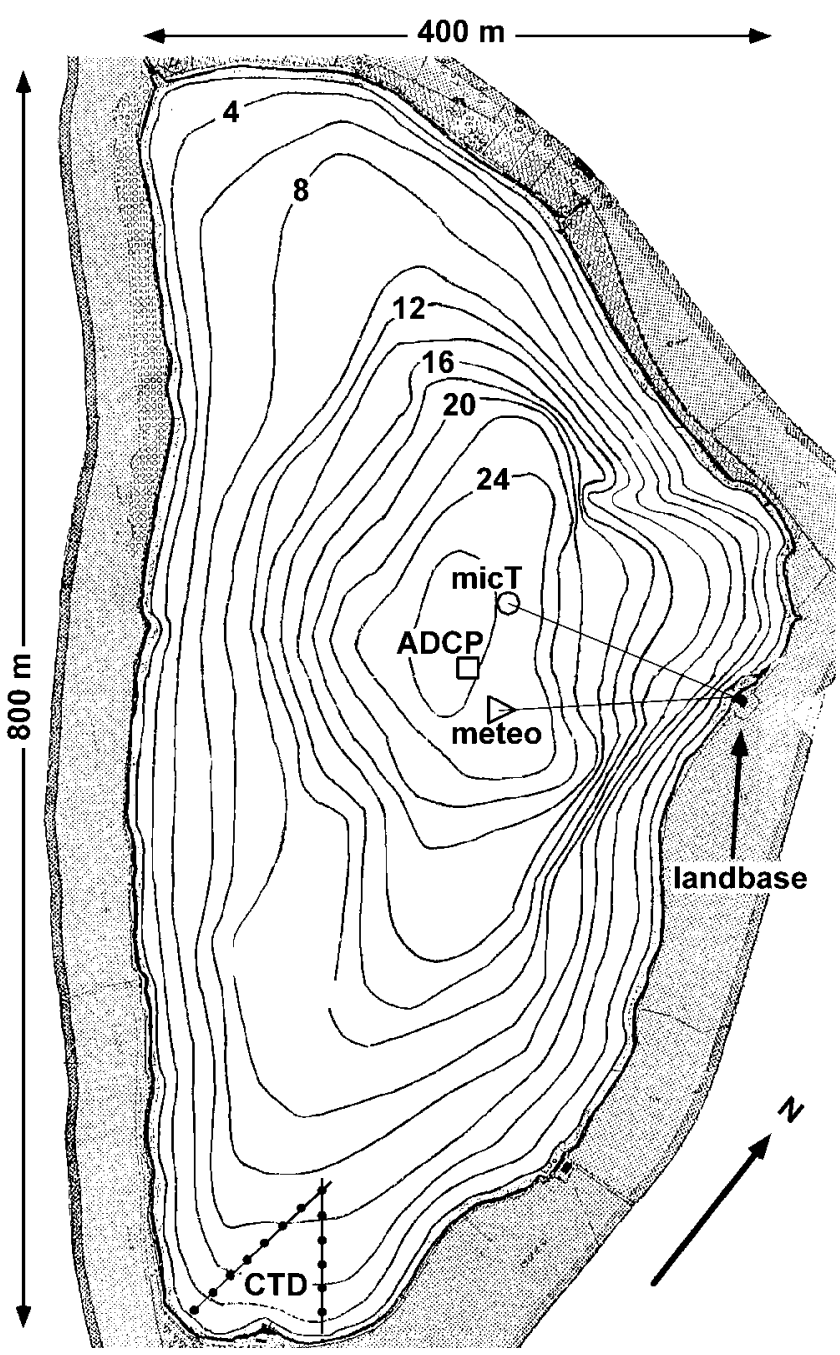

Figure 1. Site map of Soppensee, location of temperature microstructure profiler (circle), ADCP (square), meteorological platform (triangle), and CTD transects (solid circles on line).

processing before $\mathrm{A} / \mathrm{D}$ conversion, the device featured a response time of approximately $24 \mathrm{~ms}$ (I. Schuffenhauer et al., The response function of fast thermistors, submitted to Journal of Atmospheric and Oceanic Technology, 2003) for the selected profiling speed, and a HF noise level of about $10^{-4} \mathrm{~K}$. To calibrate the temperature measurements, a gauged standard temperature probe (SeaBird) was mounted close to the microstructure probes. This allowed calculating accurate heat budgets from the series of consecutive microstructure profiles. The pressure derived depth readings were calibrated via surface detection in the temperature record. Eleven self-contained TR1000 temperature loggers (Richard Brancker Research, Ottawa, Canada) were assembled onto a thermistor string and deployed at $0.5,2.5,4.5,6,7,8,9,10$, 12,17 , and $25 \mathrm{~m}$ depth, respectively.

[12] A three-beam high-resolution ADCP (Nortek, Sandvika, Norway) was deployed at a depth of $8.0 \mathrm{~m}$. Profiling over four meters upward, the instrument was set up to resolve the processes at the base of the convective layer (where $D \approx 6 \mathrm{~m}$ ). The top four meters of the water column were not investigated to obviate backscatter disturbance from the surface. Over the range of 40 depth bins, one every $10 \mathrm{~cm}$, all three velocity components were measured at an internal sampling frequency of $0.5 \mathrm{~Hz}$. The absolute measurement uncertainty was determined from a test application at the site by the manufacturer to range from $0.15 \mathrm{~mm} \mathrm{~s}^{-1}$ (closest bin) to $0.45 \mathrm{~mm} \mathrm{~s}^{-1}$ (furthest bin), for data averaged over $30 \mathrm{~s}$ [Gordon et al., 1999].

[13] Local meteorological measurements were performed from a platform mounted on two boats assembled to a catamaran. An automatic meteorological station (Aanderaa, Bergen, Norway) measured incoming and reflected solar radiation, downwelling and upwelling net radiation, wind speed, relative humidity, and air temperature. Moreover, an acoustic anemometer was deployed to track the wind speed at $20 \mathrm{~Hz}$ temporal resolution. Synchronous, coherent measurements of air temperature and water vapor concentration allowed an estimation of the vertical eddy flux of sensible and latent heat [Eugster et al., 2003].

\subsection{Batchelor Method}

[14] Batchelor [1959] theoretically estimated the form of the temperature gradient spectrum for isotropic, homogenous turbulence. Gibson and Schwartz [1963] reformulated this spectrum into a one-dimensional representation and validated its form in laboratory experiments. Since then, the comparison of model spectra and measured gradient spectra has been utilized to estimate the dissipation rate of TKE and temperature variance [e.g., Gregg et al., 1973; Carter and Imberger, 1986; Luketina and Imberger, 2001]. Here we use an associated form of the single-sided, onedimensional Batchelor spectrum $\Phi_{l d}^{B}$,

$$
\Phi_{1 d}^{B}(k)=\frac{\chi}{2 \kappa_{T}} \frac{x^{3}}{k^{3}}\left(\frac{e^{-x^{2}}}{x}-\left(\pi^{1 / 2}-2 \int_{0}^{x} e^{-y^{2}} d y\right)\right)
$$

with

$$
x=k\left(c_{B} \kappa_{T}\right)^{1 / 2}\left(\frac{\nu}{\varepsilon}\right)^{1 / 4}
$$

that allows fitting the model spectra onto temperature spectra, where the dissipation rate $\varepsilon$ of turbulent kinetic energy and the dissipation rate $\chi$ of temperature variance are the fit parameters (Figure 3a). In equation (1) $k$ is the one-dimensional wave number, $c_{B} \approx 3.4$ [Gibson and Schwartz, 1963; Grant et al., 1968; Dillon and Caldwell, 1980; Oakey, 1982] is the Batchelor constant, $v$ is the kinematic viscosity of water, and $\kappa_{T}$ is the molecular thermal diffusivity in water. Dissipation rates of TKE determined in this way from temperature microstructure measurements have been favorably tested against independent dissipation rate estimates from shear microstructure measurements [Kocsis et al., 1999].

[15] To reduce the quantization noise of the microscale temperature fluctuations, the signal was frequency preemphasized before A/D conversion [Mudge and Lueck, 1994; Gloor, 1995]. For single estimates of the dissipation rates $\varepsilon$ and $\chi$, the temperature microstructure profiles are cut into segments of 512 samples, covering a vertical range of $0.43 \mathrm{~m}$ per segment. This domain size was chosen (out of the powers of 2) as the best compromise between the 


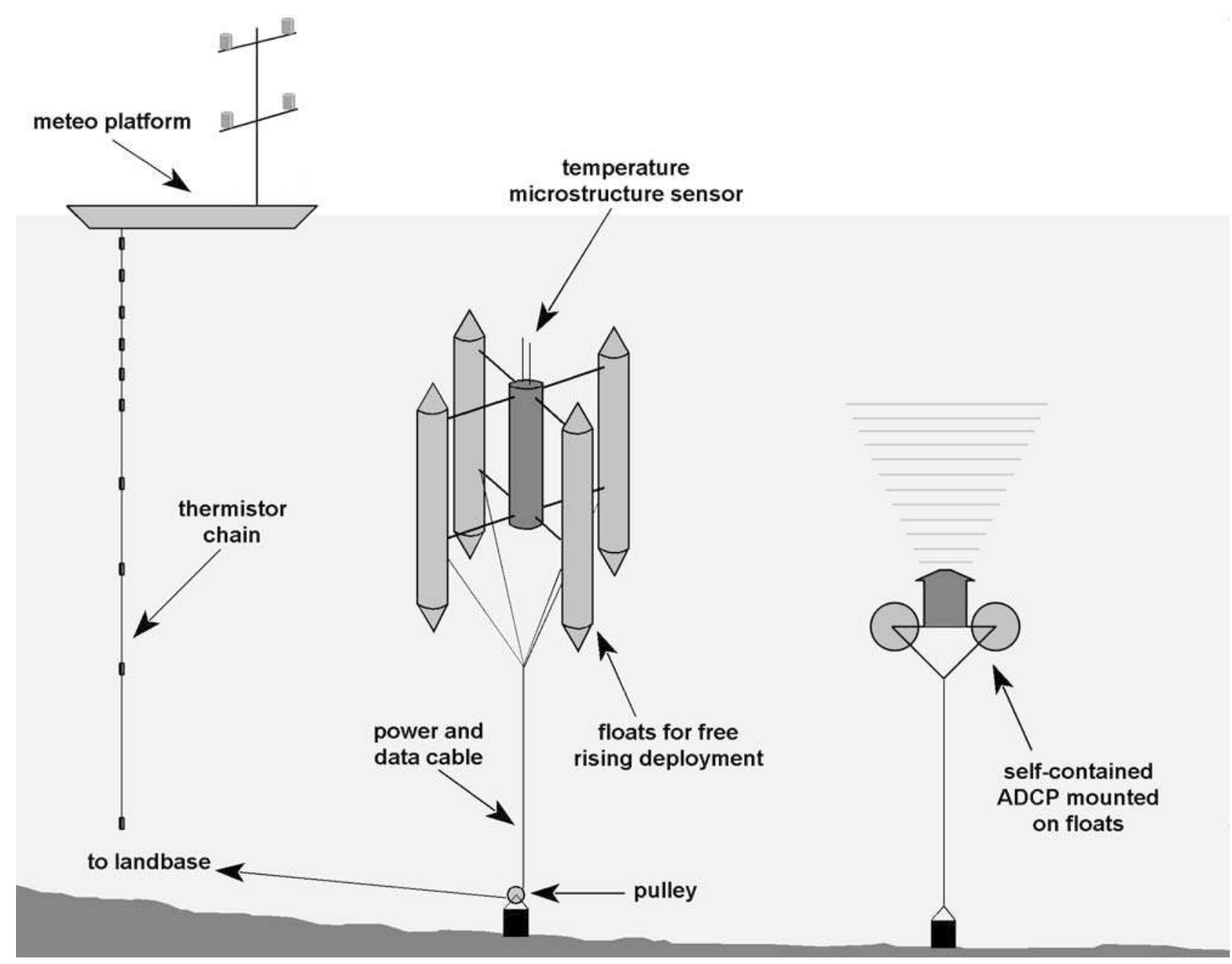

Figure 2. Experimental setup, deployment mode of the temperature microstructure profiler, ADCP, and thermistor string.

following two arguments: First, the domain is long enough to resolve dissipation rates of TKE at least down to $10^{-10} \mathrm{~W}$ $\mathrm{kg}^{-1}$, particularly because we have not applied the Welchaveraging method [e.g., Priestley, 1981] for the spectral estimates (which reduces the domain of the spectra, as it makes use of subsegments). Second, the domain is also small enough to ensure relatively homogenous turbulence within a segment, since turbulent patch sizes [e.g., Luketina and Imberger, 2001] in our data typically did not fall below 50 $\mathrm{cm}$. A discussion on the condition of isotropic turbulence follows in section 2.3.

[16] As Batchelor spectra are rather insensitive to changes in the dissipation rate $\varepsilon$ of TKE (equation (1)), the fitting procedure introduces considerable uncertainty in estimating $\varepsilon$. To compensate for this deficiency, spatial and temporal averaging of single estimates is indicated (as well as to approach the statistical ensemble mean). Apart from that, we applied two independent fitting methods for comparison. In the first method, an algorithm, developed at EAWAG, minimizes a weighted squared distance function between temperature and model spectrum in the double logarithmic domain $\left(\varepsilon_{\text {EAWAG }}\right)$. The weight compensates amongst other things for the signal-to-noise ratio. For details see Simon [1997], Gloor [1995] and Jonas [2001]. For the second method, dissipation rates were estimated from maximum likelihood fittings $\left(\varepsilon_{\text {MLE }}\right)$, using an algorithm provided by Ruddick et al. [2000]. This latter method additionally produces upper and lower fitting boundaries.

\subsection{Inertial Dissipation Method}

[17] A universal form of the velocity spectrum in the inertial subrange was suggested by Kolmogorov [1941], based upon a local isotropy similarity hypothesis,

$$
\Phi^{K}(k)=\alpha_{K} \varepsilon^{2 / 3} k^{-5 / 3},
$$

where $\Phi^{K}$ is the three-dimensional velocity power spectrum, and $\alpha_{K} \approx 1.56$ [Wyngaard and Coté, 1971; Yaglom, 1981] is the three-dimensional Kolmogorov constant. For practical purposes this spectrum can be separated into along-stream (index 1) and cross-stream (index 2) contributions [e.g., Tennekes and Lumley, 1972; Hinze, 1975] assuming isotropic conditions,

$$
\begin{aligned}
\Phi_{1}^{K}\left(k_{1}\right) & =\frac{18}{55} \alpha_{K} \varepsilon^{2 / 3} k_{1}^{-5 / 3} \\
\Phi_{2}^{K}\left(k_{1}\right) & =\frac{24}{55} \alpha_{K} \varepsilon^{2 / 3} k_{1}^{-5 / 3} .
\end{aligned}
$$



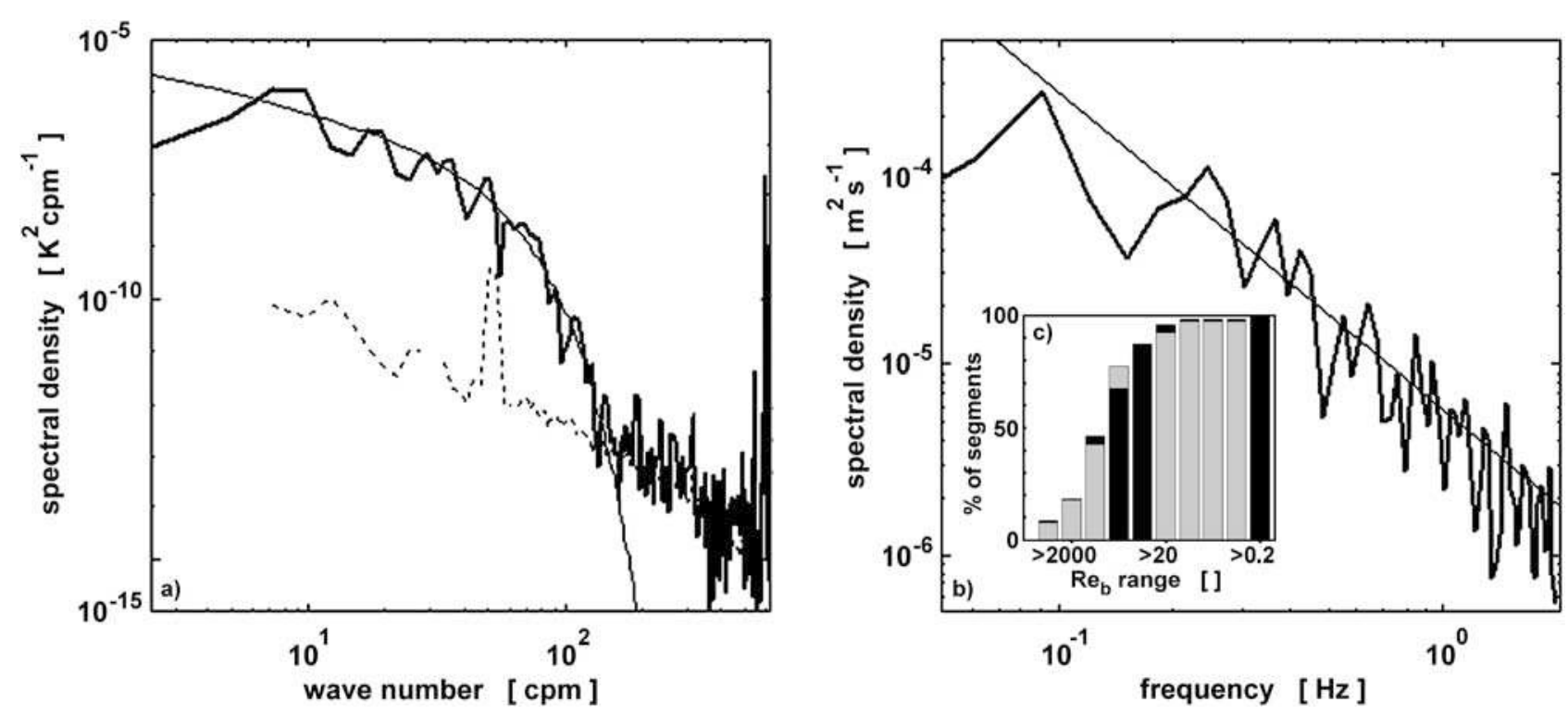

Figure 3. (a) Example of a temperature spectrum, representative of the nighttime CBL at Soppensee with a dissipation rate of TKE of $1.9 \times 10^{-9} \mathrm{~W} \mathrm{~kg}^{-1}$, temperature spectrum (thick solid line), fitted Batchelor spectrum (thin solid line, equation (1)), and campaign-specific noise level of the device (thin dotted line); (b) example of an ADCP velocity spectrum, representative of the nighttime CBL at Soppensee with a dissipation rate of $6.2 \times 10^{-9} \mathrm{~W} \mathrm{~kg}^{-1}$, velocity spectrum (thick solid line), and fit to the inertial subrange of the spectrum (thin solid line); (c) histogram of distribution of the buoyancy Reynolds number over all stably stratified segments in the CBL during periods i (gray bars) and ii (black bars) of equilibrium stage convection, where reference for periods $\mathrm{i}$ and ii is given in Figure 5; the bars denote $R e_{b}$ ranges from left to right: $>6300,>2000,>630,>200,>63,>20,>6,>2,>0.6$, and $>0$.

First experimental verifications of Kolmogorov's spectrum were obtained by Grant et al. [1962] and Gibson and Schwartz [1963], and the possibility of extracting TKE dissipation estimates from velocity spectra is now widely accepted as the so-called inertial dissipation method (IDM).

[18] Several criteria delimit the applicability of the IDM. Gargett et al. [1984] formulated the criterion

$$
\operatorname{Re}_{b}=\frac{\varepsilon}{\nu \cdot N^{2}}>200
$$

for ensuring turbulence in stably stratified waters to fulfill the isotropy assumption, where $R e_{b}$ is the buoyancy Reynolds number, and $N$ is the Brunt-Väisälä frequency. However, dilution of this criterion by one order of magnitude (i.e., $R e_{b}>20$ ) results, according to these authors, in only modest errors in the estimation of $\varepsilon$ (approximately 30\%).

[19] Additionally aiming for the condition of isotropy, the maximum wavelength that may be considered is the thickness of the relevant layer, for example, the CBL depth, as eddies must fit into the given geometry of the stratification. Other device-specific criteria target the data's spatial resolution and the noise.

[20] Since the ADCP data provide the three-dimensional velocity vector in terms of space (depth bins) and time (sampling interval), the velocity spectra over the wave number could be calculated directly from the string of velocity data along the bins. Such derived spectra, however, did not appropriately resolve the inertial subrange. As an alternative approach, the time series were transformed into spatial velocity series, assuming that eddies persist longer than it takes for them to pass by the instrument (referred to as frozen field hypothesis [Taylor, 1938]). Tennekes and Lumley [1972] drafted a criterion to validate this assumption,

$$
k_{1} \Phi_{1}^{K}\left(k_{1}\right)<\bar{u}^{2}
$$

where $\bar{u}$ is the average advection velocity.

[21] The ADCP determines velocities on the basis of three acoustic beam sampling volumes, which are horizontally separated by up to $3.2 \mathrm{~m}$ (furthest bin). Given a typical flow structure, we assume the horizontal velocity fluctuation within the three different sampling volumes to correlate well, while the vertical velocity fluctuations may not. We therefore decided to separate the horizontal flow into along-stream and cross-stream components (decomposition by means of 32 min average $=$ one temporal bin), and to estimate $\varepsilon$ by the IDM from these components only (Figure 3b).

[22] From all criteria delimiting the applicability of the IDM, the assumption of isotropy is the only one which is critical, where this assumption is likewise relevant to the Batchelor method (section 2.2). A distribution of the buoyancy Reynolds number over all stably stratified segments in the CBL during equilibrium stage convection is given in histogram Figure $3 \mathrm{c}$. Meeting $R e_{b}>200$ for $75 \%$ of the segments and $R e_{b}>20$ for $95 \%$ of segments, respectively, we may conclude that the Batchelor method and the IDM yield reliable estimations of $\varepsilon$ in the CBL during nights. This, however, may not be the case during the day and in the thermocline, following equation (4). Also applying to unstable stratification, we may not expect isotropic turbulence over all length scales. However, length scales relevant 


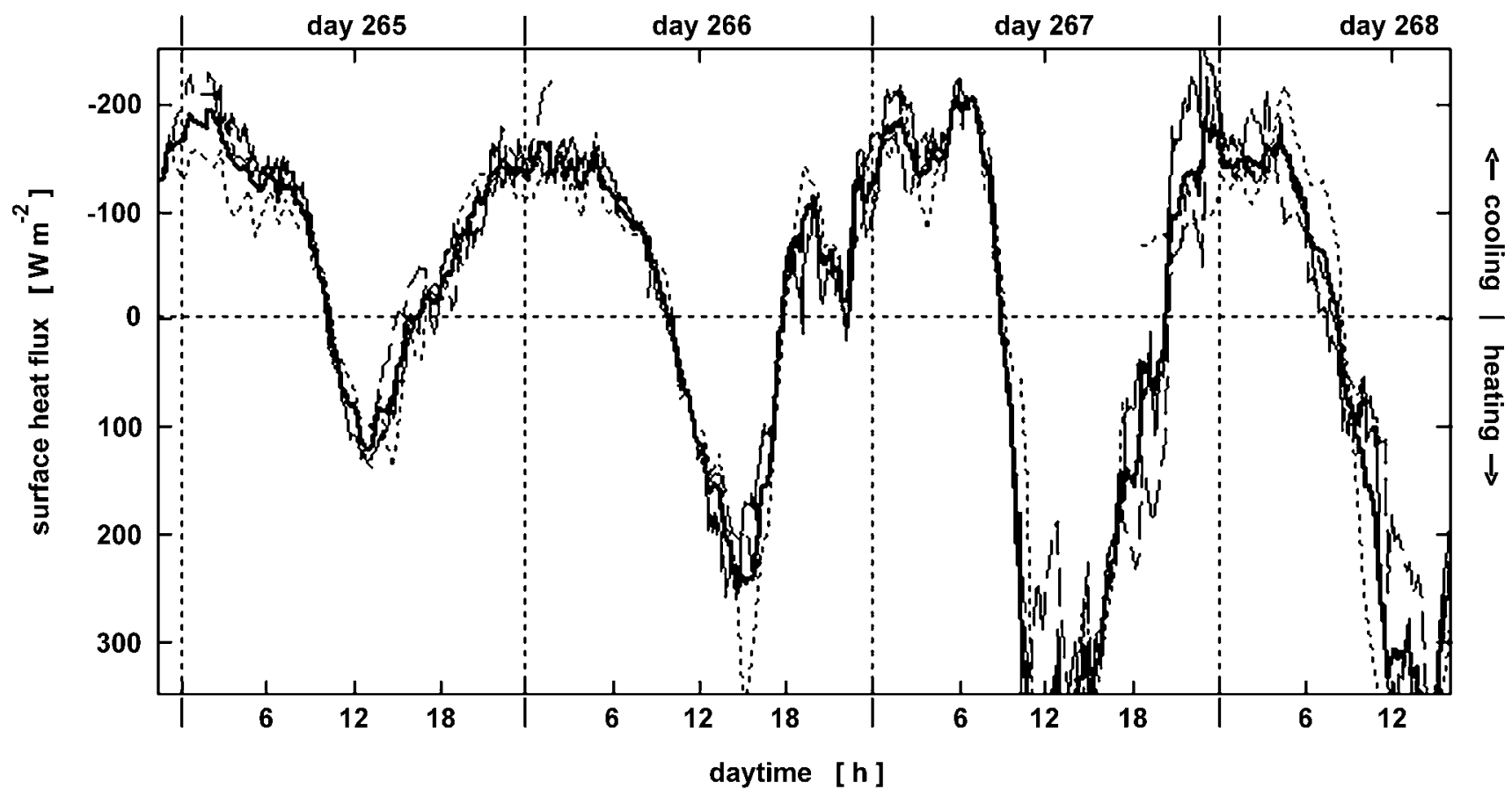

Figure 4. Surface heat flux, according to the heat budget from microstructure profiles, running mean filtered with \pm 30 min window (thin dashed line); heat budget from thermistor string data, running mean filtered with \pm 120 min window (thin solid line); residual of net radiation minus sensible and latent heat fluxes, 30 min bins (thin dot-dashed line); and the arithmetic average of the three estimates (thick solid line).

to fitting Batchelor spectra are typically below $10 \mathrm{~cm}$ (Figure 3a). Likewise, length scales relevant to fitting $-5 / 3$ slopes (IDM) are typically below $0.01 \mathrm{~m} \mathrm{~s}^{-1} / 0.1$ $\mathrm{Hz}=10 \mathrm{~cm}$ as well (Figure $3 \mathrm{~b}$ ), where $0.01 \mathrm{~m} \mathrm{~s}^{-1}$ is the typically observed current velocity. Contrary, a typical length representative of convective patch sizes would be several meters (see section 3.3). Hence there are at least two orders of magnitude between the energy containing scales (thermals) and the scales at which the turbulence is assessed and at which we may assume a sufficient degree of isotropy. Thus we expect reasonably correct estimations of $\varepsilon$ by the IDM and the Batchelor method, even where equation (4) does not apply or yield. However, especially during the days and in the thermocline, the quality of the dissipation rate estimates will be limited.

\section{Observations}

\subsection{Surface Heat Flux}

[23] The surface heat flux has been independently estimated from three different sources: (1) the temperature microstructure profiles, (2) the temperature record from the thermistor string, and (3) the meteorological radiation and eddy flux measurements. First, the former two sets of temperature data were utilized to calculate the change rate of the total heat content in the CBL. The temporal dynamics of the heat flux from the CBL into the thermocline was disregarded, since this flux represented only a small contribution to the CBL heat budget. As a result of this simplification, the bias that comes along with misinterpreting horizontally transported heat (by seiching or other reversible dislocations) could be reduced considerably. Finally, the surface heat flux was estimated from the residual of net radiation minus sensible and latent heat fluxes [Eugster et al., 2003]. Wind speed data from a sonic anemometer plus concurrent air temperature and water vapor measurements enabled estimations of sensible and latent heat fluxes with the eddy covariance method [Jones and Smith, 1977; Smith et al., 1991]. The net radiation was determined with a $360^{\circ}$ net pyrradiometer, the domes of which were actively dried from moisture by flushing with dry air.

[24] Figure 4 presents all three estimates of the surface heat flux. In general their agreement is excellent considering the various sources of possible inaccuracies of each method. No systematic bias of one of the estimations is detected. Typical discrepancies amount to about $25 \mathrm{~W} \mathrm{~m}^{-2}$. As it is not obvious which one of the three methods provides the most reliable estimates, we determined the nonweighted average for further analysis (Figure 4, thick solid line). During the 4 day period considered in this study, the nightly heat loss was at a relatively constant level of around $150 \mathrm{~W} \mathrm{~m}^{-2}$, for approximately 10 hours each night. Conversely, the daytime heating became stronger during the study period, doubling in intensity from day 265 to 266 , and again from day 266 to 267.

\subsection{Diurnal Stratification Dynamics of the CBL}

[25] The temperature record from the thermistor string (Figure 5) shows the effect of the surface heat flux on the temporal dynamics of the stratification. After the nightly convection, the CBL is quasi-mixed in the morning. Because of the solar heating, it regains the typical stable fair weather stratification during daytime. As this restratification process intensifies from day to day during the study 


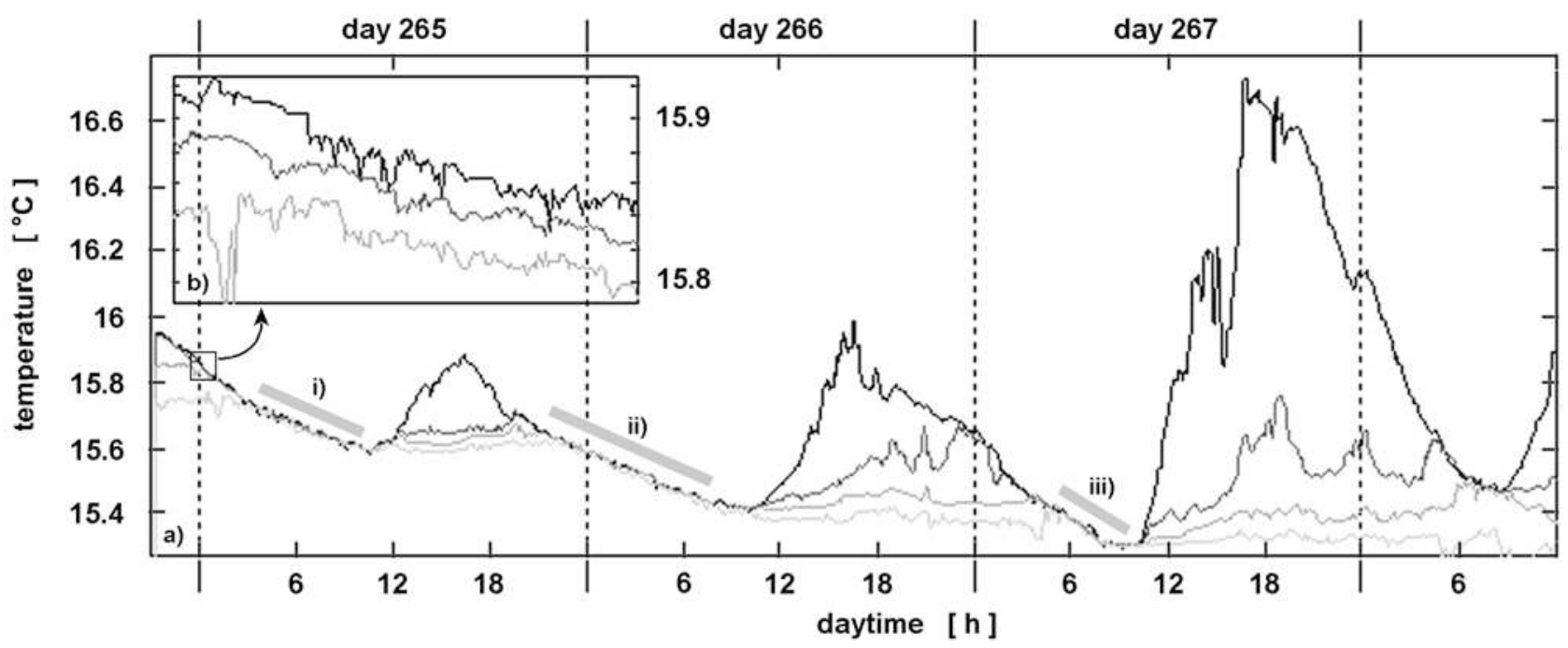

Figure 5. (a) Temperature of the top four units of the thermistor string at 0.5 (black line), 2.5 (dark gray line), 4.5 (gray line), and $6.0 \mathrm{~m}$ (light gray line) depth. (b) Plots staggered by $0.02 \mathrm{~K}$ each. The gray bars demark periods of equilibrium stage convection: (i) day 265 from 0300 to 1000 LT, (ii) from day 265 at 2100 LT to day 266 at 0800 LT, and (iii) day 267 from 0500 to 0900 LT.

period, the convection faces an increasing temperature gradient in the evenings to be destroyed before the CBL can deepen beyond its remnant depth. Consequently, reestablishing a quasi-mixed CBL takes longer from night to night: approximately 6 hours the first entirely recorded night (1600 to 2200 LT on day 265), already 12 hours the second night (1600 to 0400 LT on days 266/267), and over 17 hours the third night (1600 to 0900 LT on days 267/268, CBL was not fully reestablished). This, in turn, allows the quasi-mixed $\mathrm{CBL}$ to be cooled for about 12 hours during nights $264 / 265$ and $265 / 266$, but only for about 6 hours the succeeding night $266 / 267$. In the following, we will focus on these periods with fully developed CBL (i.e., $D^{*}=D, D^{*}$ is determined as the depth of the first occurrence of an overturning eddy $(\partial T / \partial z=0)$ when analyzing the temperature stratification from the inner thermocline upward).

[26] Consecutive nighttime temperature microstructure profiles (Figure 6) reveal an average stratification of the fully developed CBL that differs characteristically from a mixed layer: beneath a thin super-adiabatic surface sublayer of approximately $50 \mathrm{~cm}$ thickness, the average stratification features a neutral stability almost linearly increasing to $N^{2}=3 \times 10^{-5} \mathrm{~s}^{-2}$ at the base of the convective layer, similar to corresponding observations by Imberger [1985], Anis and Moum [1994], and Brainerd and Gregg [1997]. This stratification pattern remains despite intense cooling over the entire CBL. We rate this observation as very reliable, because the temperature records from the thermistor string as well as from the regular temperature probe of the microstructure profiler independently confirm the finding.

\subsection{Current Pattern of the CBL}

[27] The velocity profiles measured by the ADCP reveal a diurnal cycle in the current pattern (Figure 7). During the day, vertical velocities were observed typically below $1 \mathrm{~mm}$ $\mathrm{s}^{-1}$ and, in general, did not develop much spatial or temporal structure. In contrast, during periods with significant heat loss to the atmosphere, episodes with vertical velocities of alternating direction up to $-7 /+4.5 \mathrm{~mm} \mathrm{~s}^{-1}$ were present in the water column, indicating homogeneous plumes passing by the profiler (Figure 7e). These enhanced vertical velocities were, however, restricted to the CBL plus the adjacent entrainment zone $\left(0<z<\approx 1.1 D^{*}\right)$. Remarkably, the downward plumes generally featured higher velocities (typically $3-6 \mathrm{~mm} \mathrm{~s}^{-1}$ ) than the upward plumes (typically 2-3 $\mathrm{mm} \mathrm{s}^{-1}$ ) (Figure 7d). Accordingly, the velocity histogram displays an asymmetric distribution (Figure 7a): no upward velocities above $4.5 \mathrm{~mm} \mathrm{~s}^{-1}$ were recorded. However, a high occurrence of upward velocities in the range of $1-2 \mathrm{~mm} \mathrm{~s}^{-1}$ allowed an overall balanced mass flux budget.

[28] To trace the horizontal diameter of plume cores, the vertical velocity component was plotted against the horizontal advection path. Regions with vertical velocities exceeding certain threshold values were encircled (Figure 7c). Maximum core diameters of plumes were identified to be on the order of $5 \mathrm{~m}$ (Figure 7c), similar to direct observations from a submarine by Thorpe et al. [1999] in Lake Geneva (Switzerland) during corresponding conditions. Note that the estimated velocities are based on single-point measurements in three sample volumes, which are horizontally apart according to the bin's lag to the ADCP in combination with the beam angle $(3.2 \mathrm{~m}$ for the furthest bin). Therefore the plume sizes can only be roughly estimated. Unfortunately, any analysis of the plume sizes in terms of depth would be biased.

\subsection{Dissipation Rate of Turbulent Kinetic Energy}

[29] Three evaluation series for the dissipation rate of TKE are available: the two estimates on the basis of temperature microstructure profiles $\varepsilon_{E A W A G}$ and $\varepsilon_{M L E}$, as well as the ADCP data derived estimates $\varepsilon_{A D C P}$. Unfortunately, we were only able to collect a complete series of microstructure profiles during the first night. During the following three nights, the availability of high-quality data is only incomplete for technical reasons. In some cases the profiler was malfunctioning, in other cases the data was disturbed by noise, which did not allow for a reliable 

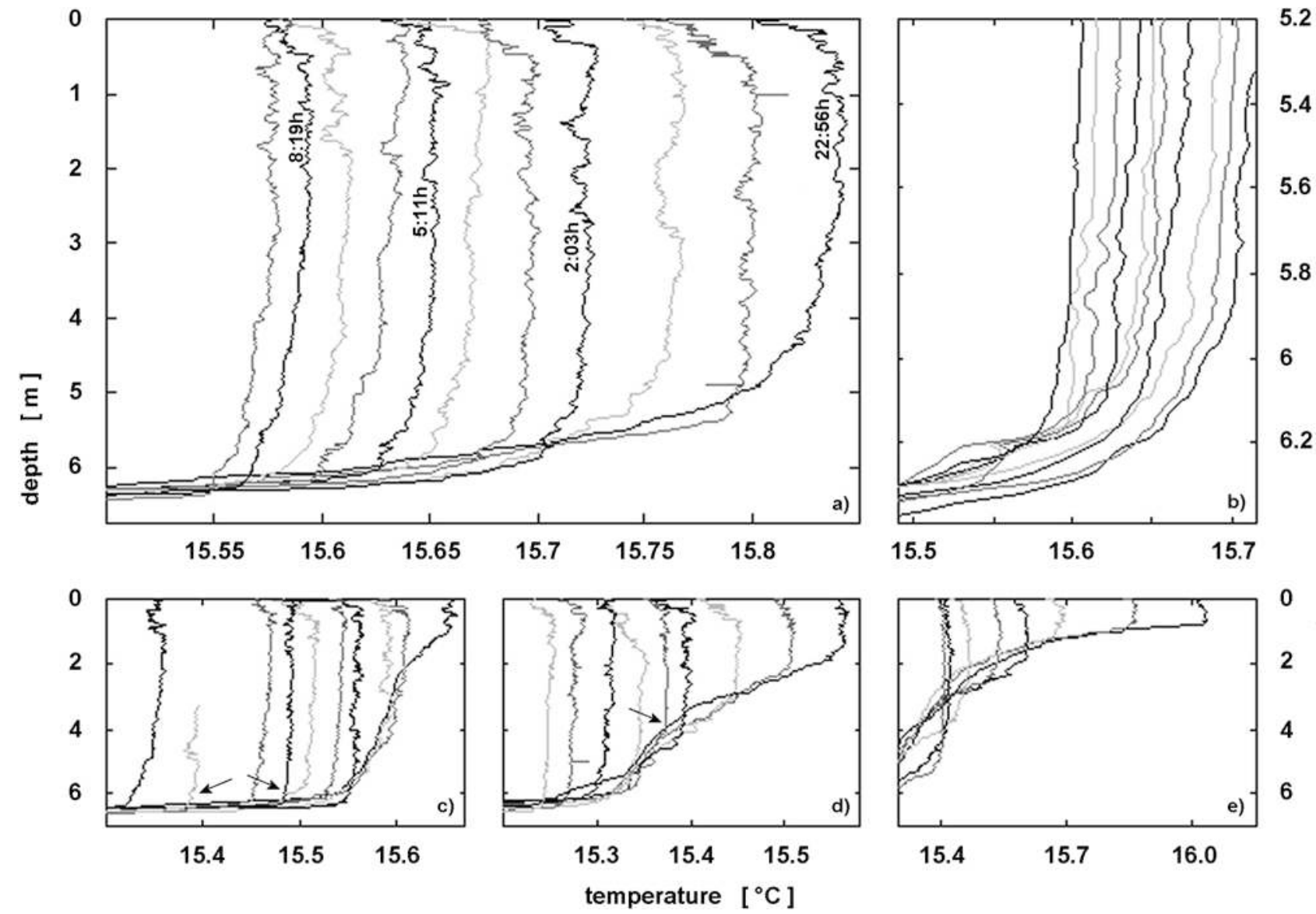

Figure 6. Dynamics of the temperature stratification during the nights averaged over four profiles each: (a) hourly profiles between day 264 at 2256 LT and day 265 at 0922 LT; (b) half-hourly profiles between day 265 at 0203 and 0644 LT; (c) hourly profiles between day 265 at 1848 LT and day 266 at 0209 LT, with additional profiles of day 266 at 0541 and 0913 LT; (d) hourly profiles between day 267 at 0025 and 0851 LT; and (e) hourly profiles between day 268 at 0058 and 0825 LT. Arrows indicate profiles during a wind-influenced regime (section 4.1).

analysis. However, the temporal and spatial dynamics of $\varepsilon$ in the CBL is largely covered. As the top $4 \mathrm{~m}$ of the $\mathrm{CBL}$ were not resolved by the ADCP (see section 2.1), the usability of $\varepsilon_{A D C P}$ with respect to the TKE budget is limited. Note again, that the used methods were deployed partially outside the appropriate application domain (section 2.3).

[30] A compilation of the three estimates of the dissipation rate of TKE is given in Figure 8. In general, all three dissipation rate estimates expectedly follow the stratification pattern: Considerable dissipation of TKE occurs primarily in zones with little or no stability and increases on average toward the surface. Moreover, significant dissipation rates below the interface $D^{*}$ provide evidence of turbulent mixing in the entrainment zone. With typical gradient Richardson numbers for this depth range at about 50 , shear will not contribute significantly to the generation of TKE [Thorpe, 1969; Peters et al., 1988]. Therefore we may attribute the turbulence in the entrainment zone to convective plumes penetrating into the upper thermocline (Figure 7e).

[31] Comparing the two temperature microstructure derived dissipation rates, $\varepsilon_{M L E}$ displays on average slightly higher values (see also section 4.2). This might stem from fitting in the logarithmic domain in the case of $\varepsilon_{E A W A G}$, contrary to the maximum likelihood method. Furthermore, unexplained discrepancies were observed during two short periods around midnight on day $265 / 266$ between $\varepsilon_{E A W A G}$ and $\varepsilon_{M L E}$ and around 0600 LT on day 267 between $\varepsilon_{M L E}$ and $\varepsilon_{A D C P}$.

\section{Discussion}

\subsection{Active Stabilization of the Lower Convective Layer}

[32] In spite of cooling and mixing over the entire vertical range of the $\mathrm{CBL}$, the lower bulk of the layer remains stably stratified. Thus an enhanced heat flux out of the lower CBL must actively support the excess stratification. The following four mechanisms may cause such a heat flux, of which all but the last can be rejected.

[33] 1. Lateral advection of large-scale horizontal temperature gradients: As the heat flux to the atmosphere is approximately homogenous over the lake, the CBL cools inversely proportional to the mixing layer depth $D^{*}$ (i.e., more intensively in the shallow shore regions). This results in a horizontally inhomogeneous temperature distribution in the CBL and a respective lateral exchange flow [e.g., Horsch and Stefan, 1988; Sturman et al., 1999]. With the 

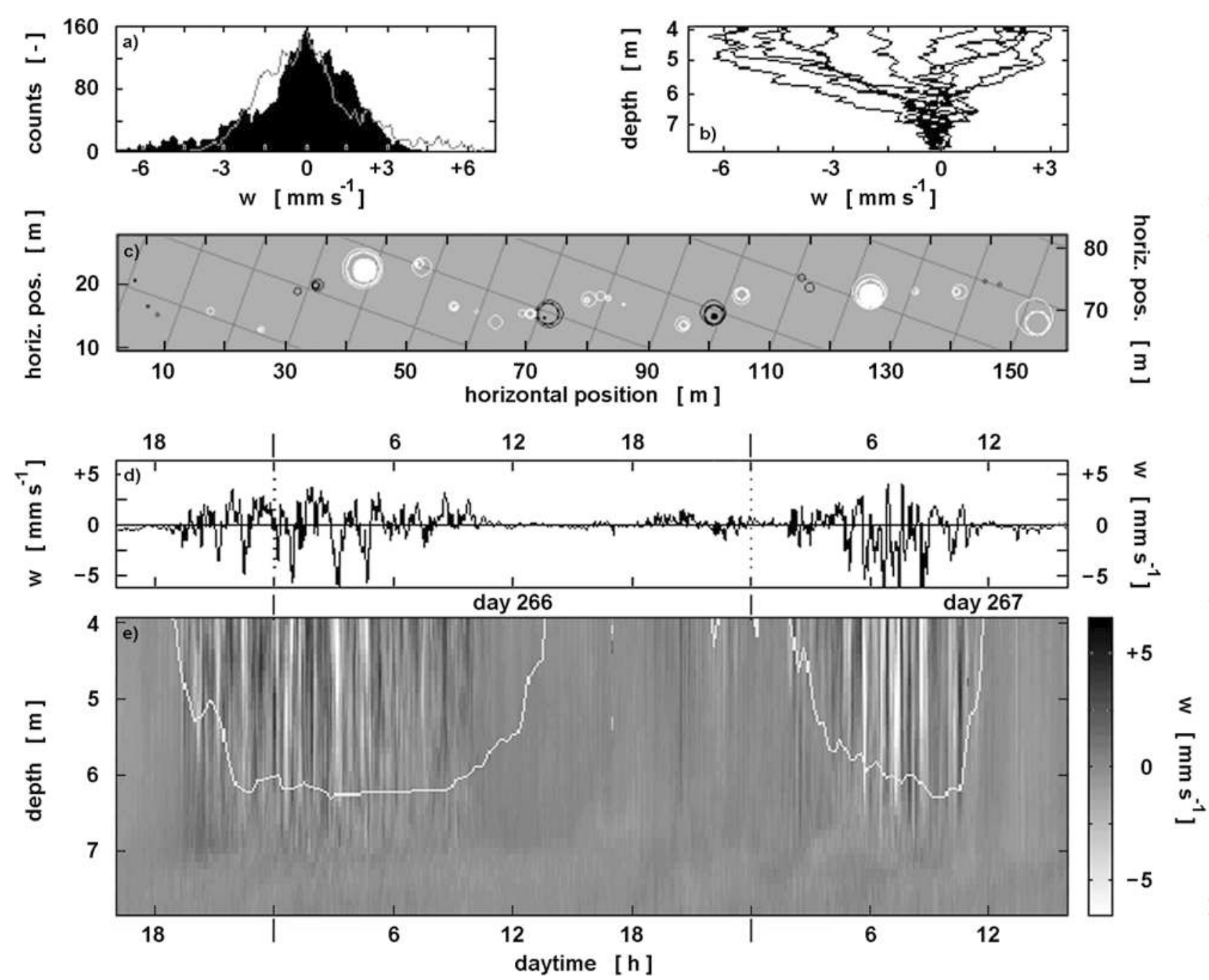

Figure 7. Vertical velocity component (positive upward) as measured by the ADCP: (a) distribution at the top bin at $4.0 \mathrm{~m}$ depth (black histogram) and its inversion in $\mathrm{w}$ for comparison (gray line), evaluated from the 15 hour period after day 265 at $1900 \mathrm{LT}$ and from the 10 hour period after day 267 at $0200 \mathrm{LT}$; (b) profiles of vertical velocities representative of the core of convective plumes, evaluated from equilibrium stage convection period ii, reference is given in Figure 5; (c) at the top bin at $4.0 \mathrm{~m}$ depth plotted along the path integral of the horizontal advection velocity, circles enclose areas of the vertical flow: $\mathrm{w}>2 \mathrm{~mm} \mathrm{~s}^{-1}$ (thin black circles), $\mathrm{w}>3 \mathrm{~mm} \mathrm{~s}^{-1}$ (thick black circles), $\mathrm{w}>4 \mathrm{~mm} \mathrm{~s}^{-1}$ (solid black circles), $\mathrm{w}<-2 \mathrm{~mm} \mathrm{~s}^{-1}$ (thin white circles), $\mathrm{w}<-3 \mathrm{~mm} \mathrm{~s}^{-1}$ (thick white circles), $\mathrm{w}<-4 \mathrm{~mm} \mathrm{~s}^{-1}$ (solid white circles), evaluated from the 6 hour period after day 265 at $0100 \mathrm{LT}$; (d) at the top bin at $4.0 \mathrm{~m}$ depth; and (e) over the full observed depth range; the white line demarks the temporary CBL depth $D^{*}$.

given geometry and stratification of the lake, an intrusion of cold water is expected from the shore inward, most likely along the base of the CBL. To quantify the heat flux connected to such horizontal flow, conductivity-temperature-depth (CTD) transects have been taken consecutively along two shallow slopes of the lake (Figure 1) during convection. The CTD transects display a slight tilt of the temperature isopleths in the convective layer (Figure 9a). However, no cold slope layer [Fer et al., 2002] developed capable of causing significant cold water intrusions into the lower convective layer. The heat loss per volume (averaged over the quasi-mixed part of the water column) was found to increase significantly toward the shore, indicating differential cooling (Figure 9b). Conversely, the heat loss per surface area decreased toward the shore. As the contribution of the heat exchange with the atmosphere to the net heat loss per surface area is constant, differences in this net heat loss between neighboring stations reveal a horizontal heat flux. The data do not allow accurate quantification of horizontal heat fluxes, but the significant effects obviously decay within the first $70 \mathrm{~m}$ from the shore. Moreover, given the fact that the estimations of the surface heat flux on the basis of CBL heat budgets and from atmospheric measurements coincide excellently, we may exclude the existence of systematical lateral heat fluxes. This argument also excludes other lateral effects, such as the gravitational relaxation of lateral into vertical density gradients [Brainerd and Gregg, 1997] or the intrusion of cold water from inflows (not existing in the lake under consideration).

[34] 2. Steady state heat flux through the thermocline: The thermal diffusivity through the thermocline is on the order of $10^{-7} \mathrm{~m}^{2} \mathrm{~s}^{-1}$ (close to molecular). Higher turbulent 


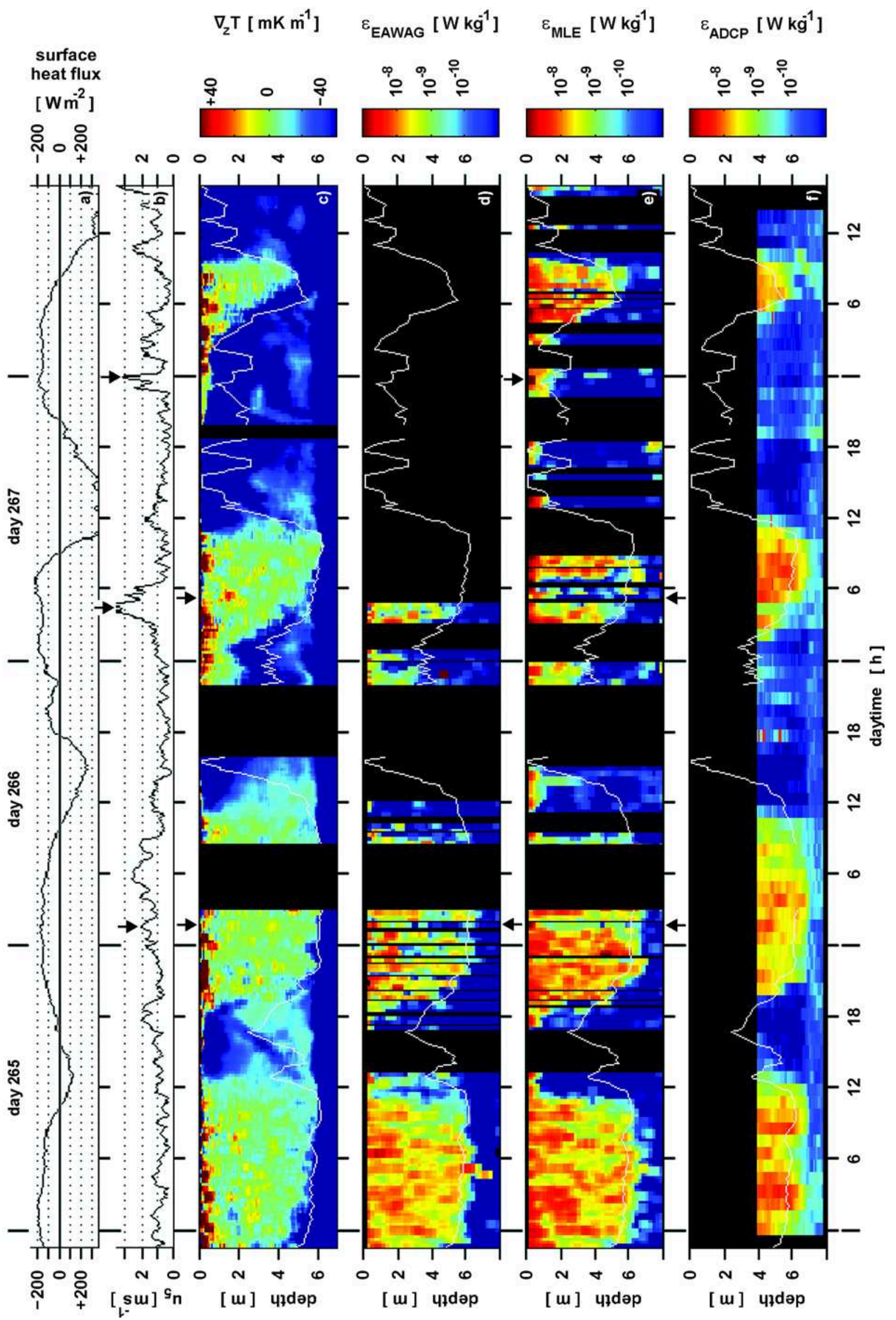



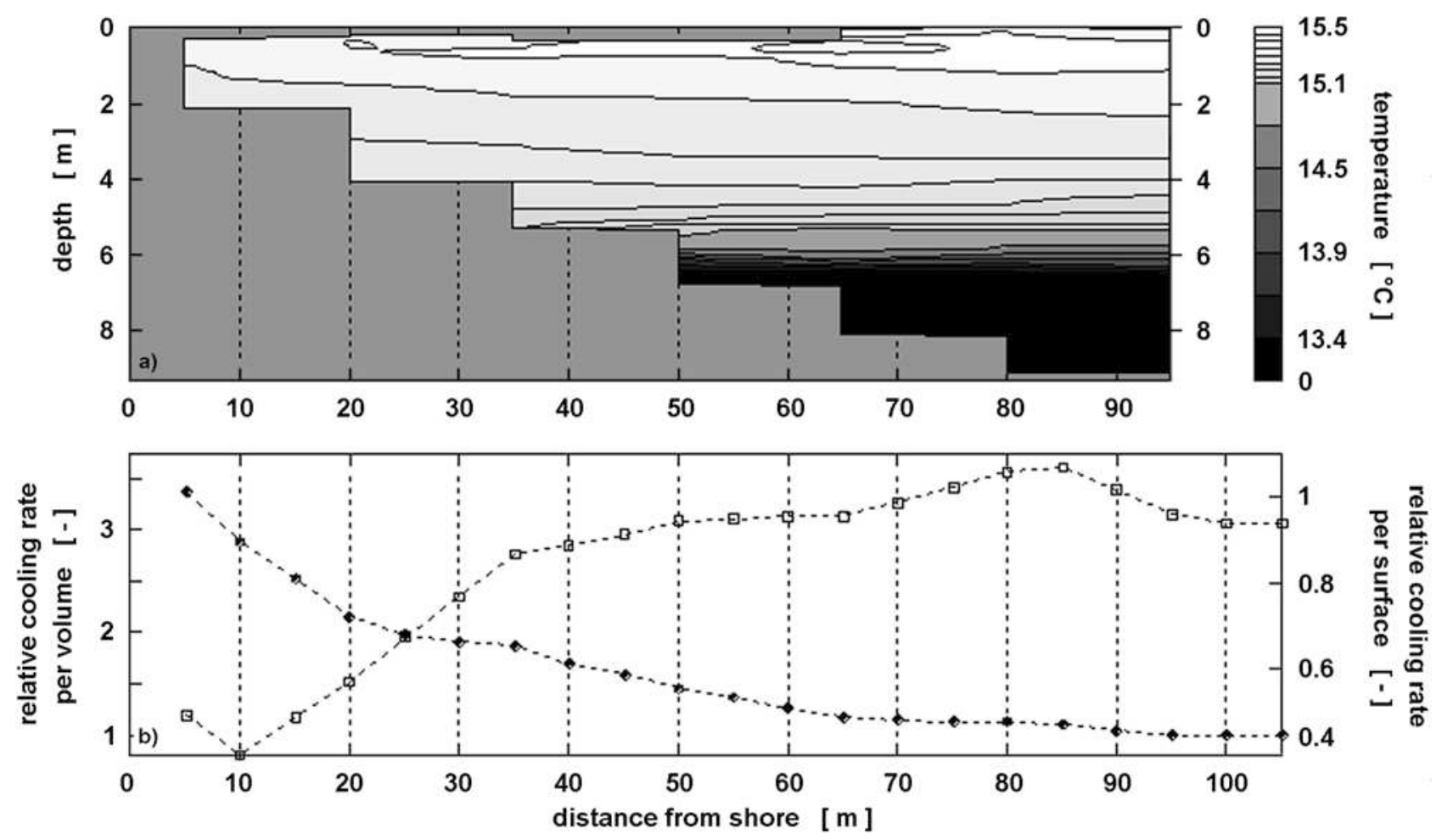

Figure 9. (a) CTD transect through shallow slope of the lake (Figure 1) and (b) cooling rates per surface area (open squares) and per volume (solid circles), scaled by the respective values representative of the center of the lake.

diffusivities would require dissipation rates $\varepsilon$ of TKE on the order of $10^{-8} \mathrm{~W} \mathrm{~kg}^{-1}$, given $N^{2} \approx 5 \times 10^{-3} \mathrm{~s}^{-2}$ in the thermocline and a mixing efficiency of $10 \%$. However, apart from the upper thermocline and single patches of temperature finestructures in the interior, the bulk of the thermocline does not feature any signs of turbulence, and $\varepsilon \ll 10^{-10} \mathrm{~W} \mathrm{~kg}^{-1}$. Thus the steady state heat flux through the thermocline amounts to around $2.5 \mathrm{~W} \mathrm{~m}^{-2}$, which is negligible against the driving surface heat flux.

[35] 3. Cooling of the base of the CBL at the expense of the thermocline: As discussed above, temperature microstructure as well as ADCP data provide evidence of penetrative convection. Even so, the upper thermocline is rather cooling than warming (Figure $6 \mathrm{~b}$ ) after $D^{*}$ reaches the remnant mixed layer depth $D$, setting the beginning of the equilibrium stage convection (i.e., after 0230 LT for day 265). Thus the upper thermocline does not accumulate heat from the lower CBL. Convective plumes penetrating into the thermocline drive turbulent mixing at the interface. As with 1 and 2, the simultaneous heat loss of upper thermocline and lower CBL can only be caused by an upward heat flux.

[36] 4. Intrusion of cold water from the super-adiabatic surface sublayer: To enable intrusion of surface water chiefly at the base of the CBL, the surface water must transverse the center bulk of the CBL without much entrainment. We suggest that this becomes possible if most of the surface water is transported in the core of isolated, broad plumes, as the entrainment area of well-developed plumes is small relative to its volume. Toward the base of the convective layer, the entrainment increases with the increasing stability of the penetrated stratification. As lateral or upward intrusions of cold water into the lower CBL could be excluded (1-3), we suggest intrusion of cold surface water from the super-adiabatic sublayer to account for the active stabilization of the lower convective layer. In the following we analyze the available data for evidence of such an entrainment regime.

[37] The ADCP data provide an indication that strong downward plumes are embedded in a less canalized upward flow (section 3.3). Studies on free convection in the ocean report similar flow regimes [e.g., Marshall and Schott, 1999]. For the case of shear-free convective boundary layers we are not aware of any empirical field study particularly addressing an asymmetric flow regime. However, several authors of large-eddy simulation (LES) studies on convective boundary layers discuss similar findings. Sander et al. [2000] report the upflows in the CBL to systematically cover around $60 \%$ of the horizontal cross-sectional area. Qualitatively similar results were obtained by Mason [1989] and Mironov et al. [2000] expressed by the vertical velocity skewness $\left\langle w^{\prime} w^{\prime} w^{\prime}\right\rangle /\left\langle w^{\prime} w^{\prime}\right\rangle^{3 / 2}$. Both studies present horizontal cross sections of the vertical flow pattern for different

Figure 8. (opposite) (a) Surface heat flux (identical to thick solid line in Figure 4); (b) wind speed at $5 \mathrm{~m}$ height; (c) vertical temperature gradient evaluated upon $20 \mathrm{~cm}$ segments; (d) $\varepsilon_{E A W A G}$ (Batchelor method, EAWAG fitting algorithm); (e) $\varepsilon_{M L E}$ (Batchelor method, Maximum likelihood estimations); and (f) $\varepsilon_{A D C P}$ (inertial dissipation method); arrows indicate the effects due to freshening winds; the white line demarks the temporary CBL depth $D^{*}$. 
depths within the CBL (in the following their indications of vertical direction are interchanged, since they modeled the atmospheric $\mathrm{CBL}$ ).

[38] In favorable agreement with our ADCP measurements (Figures 7b and 7d) Mironov et al. [2000, Figure 1] report downward peak velocities in the center of plumes approximately twice as high as the corresponding peak velocities of upflows. Even more remarkable, their zero velocity isopleths reveal a picture suggesting that, indeed, comparably little entrainment takes place at the plume edges in the depth range of $0.3 D^{*}<z<0.7 D^{*}$. In this center bulk of the CBL, the organization of the downflow area increases with depth for approximately round plumes at $z=0.7 \mathrm{D}^{*}$ embedded in the remaining area covered by the upflow. At the same time the area ratio upflow/downflow remains rather constant. Only at $z=0.9 D^{*}$ does the structure fall apart to a rather scattered distribution of upflow and downflow areas indicating severe entrainment. Hence our conclusions seem consistent with corresponding LES.

[39] Another support of the suggested flow regime is provided by the thermistor string data (Figure $5 \mathrm{~b}$ ). The temperature record from the thermistor at $z=2.5 \mathrm{~m}$ $\left(\approx 0.5 D^{*}\right)$ displays a characteristic 'archway' pattern. This imprint indicates well developed strong downward plumes embedded in background upward flow and the absence of significant entrainment. The temperature difference between plume cores and ambient water would be about $0.02 \mathrm{~K}$ (Figure $5 \mathrm{~b}$ ), which excellently coincides with the difference between the surface temperature and the temperature of the center bulk of the CBL (Figure 6a). Expectedly (according to the mentioned LES studies), this 'archway' pattern is not present in the temperature record of the neighboring thermistors at $z=0.5 \mathrm{~m}\left(\approx 0.1 D^{*}\right)$ and $z=4.5 \mathrm{~m}\left(\approx 0.95 \mathrm{D}^{*}\right)$.

[40] Vertical profiles of the vertical velocity during equilibrium stage convection (period ii); reference is given in Figure 5) were singled out as representative of the core of convective plumes (Figure 7b). Remarkably, in the center of the CBL down to around $z=5 \mathrm{~m}\left(\approx 0.80 \mathrm{D}^{*}\right)$ the vertical velocities were found to be approximately constant with depth. Only below this level did the velocities drop off quasi linearly toward the entrainment zone underneath the CBL. This finding corresponds well to LES by Mason [1989]. We read the observed velocity structure as another indication of reduced entrainment in the center bulk of the $\mathrm{CBL}$ and enhanced entrainment at the base of this layer.

[41] Fitting to our scenario, the convective regime displays a remarkable response to moderate winds. Episodes with wind speed $\underline{u}_{5 m}>2 \mathrm{~m} \mathrm{~s}^{-1}$, surface heat flux $H<-100 \mathrm{~W} \mathrm{~m}^{-2}$, and available dissipation rate profiles $\varepsilon_{M L E}$ are indicated by arrows in Figure 8 . It seems that enhanced winds, as an effect of stress-induced stirring, destroy the super-adiabatic top layer (Figure 8c), attenuating the driving mechanism of the strong downward plumes and thus interrupting the asymmetric flow pattern. A well-mixed CBL reestablishes (Figures $6 \mathrm{c}$ and $6 \mathrm{~d}$, respective profiles demarked by arrows), and the turbulence is focused near the surface (Figures $8 \mathrm{~d}$ and $8 \mathrm{e}$, see arrows). These findings indicate quasi wind-free conditions $\left(\underline{u}_{5 m}<1 \mathrm{~m} \mathrm{~s}^{-1}\right)$ to be prerequisite for the asymmetric flow pattern and for the observed stratification. The regime's response to changing winds seems to be a matter of an hour.
Table 2. Mean Scaled Production and Dissipation of TKE

\begin{tabular}{lcc}
\hline \multicolumn{1}{c}{ Source } & $\frac{1}{J_{b}^{0}} \int_{\sim 1.2}^{0} \varepsilon d \zeta$ & $\frac{1}{J_{b}^{0}} \int_{\sim 1.2}^{0} J_{b} d \zeta$ \\
\hline Mironov et al. [2000] & $\sim-0.37$ & $\sim 0.37$ \\
Mason [1989] & $\sim-0.35$ & $\sim 0.35$ \\
EAWAG (i, ii) & -0.15 & n.a. \\
MLE (i, ii) & $-0.20(-0.15 /-0.27)$ & n.a. \\
MLE (i, ii), exp. ${ }^{\mathrm{b}}$ & -0.22 & n.a. \\
Equation (9) $^{\mathrm{d}}$ & n.a. & $\sim 0.19^{\mathrm{e}}$ \\
\hline
\end{tabular}

${ }^{a}$ Estimations of $\varepsilon_{E A W A G}$ averaged over periods $\mathrm{i}$ and ii as demarked in Figure 5 .

bestimations of $\varepsilon_{M L E}$ averaged over periods $\mathrm{i}$ and ii as demarked in Figure 5; values in brackets give respective averages of the lower and upper fitting boundary.

${ }^{c}$ As MLE (i, ii) but values toward surface extrapolated to $\varepsilon / J_{b}^{0}=1$.

${ }^{\mathrm{d}}$ Estimations of $J_{b}(z)$ from temperature microstructure data using equation (9).

${ }^{\mathrm{e}}$ Note that this value is affected by inaccuracies due to seiching-induced displacements of the thermocline (section 4.2).

[42] Concluding, diverse observations suggest that cold surface water intrudes directly to the lower CBL, thereby maintaining the observed temperature stratification. Strong downward plumes transport cold surface water toward the base of the convective layer, where the organized flow structure keeps the entrainment in the center of the layer at a small level.

\subsection{Turbulent Kinetic Energy Budget}

[43] In an ideal, mixed CBL, nonpenetrative and steady state convection should cause the buoyancy flux $J_{b}$ to decrease linearly from $J_{b}^{0}$ at the surface to zero at the base of the CBL [e.g., Deardorff, 1970]. Hence the mean dissipation rate of TKE in the CBL should equal half of the surface buoyancy flux; that is,

$$
\frac{1}{D^{*}} \int_{C B L} \varepsilon \cdot d z=\frac{1}{2} J_{b}^{0}
$$

Several observations in quasi shear-free CBLs of the ocean and lakes indicate indeed average dissipation rates in good agreement to parameterization 6 [e.g., Imberger, 1985; Shay and Gregg, 1986]. However, our data reveal a different picture with a mean $\varepsilon / J_{b}{ }^{0}$ of around 0.20 (Table 2 and Figure 10b). The buoyancy flux $J_{b}$, a measure of the generation rate of TKE, provides an explanation for this discrepancy. The TKE budget reads

$$
\frac{\partial}{\partial t} T K E=J_{b}-F-\varepsilon
$$

with

$$
\begin{gathered}
J_{b}=g \alpha\left\langle w^{\prime} T^{\prime}\right\rangle \\
F=\frac{\partial}{\partial z}\left\langle w^{\prime} T K E\right\rangle-\frac{\partial}{\partial z}\left\langle\frac{1}{\rho} w^{\prime} p^{\prime}\right\rangle
\end{gathered}
$$

where $F$ is the vertical divergence of the TKE flux, consisting of the turbulent flux $\left\langle w^{\prime} T K E\right\rangle$ and pressure flux $\left\langle w^{\prime} p^{\prime} / \rho\right\rangle$. These budget terms have been resolved in LES studies by Lenschow et al. [1980], Mason [1989], and Mironov et al. [2000] (Figure 10c). Averaging equation (7) 

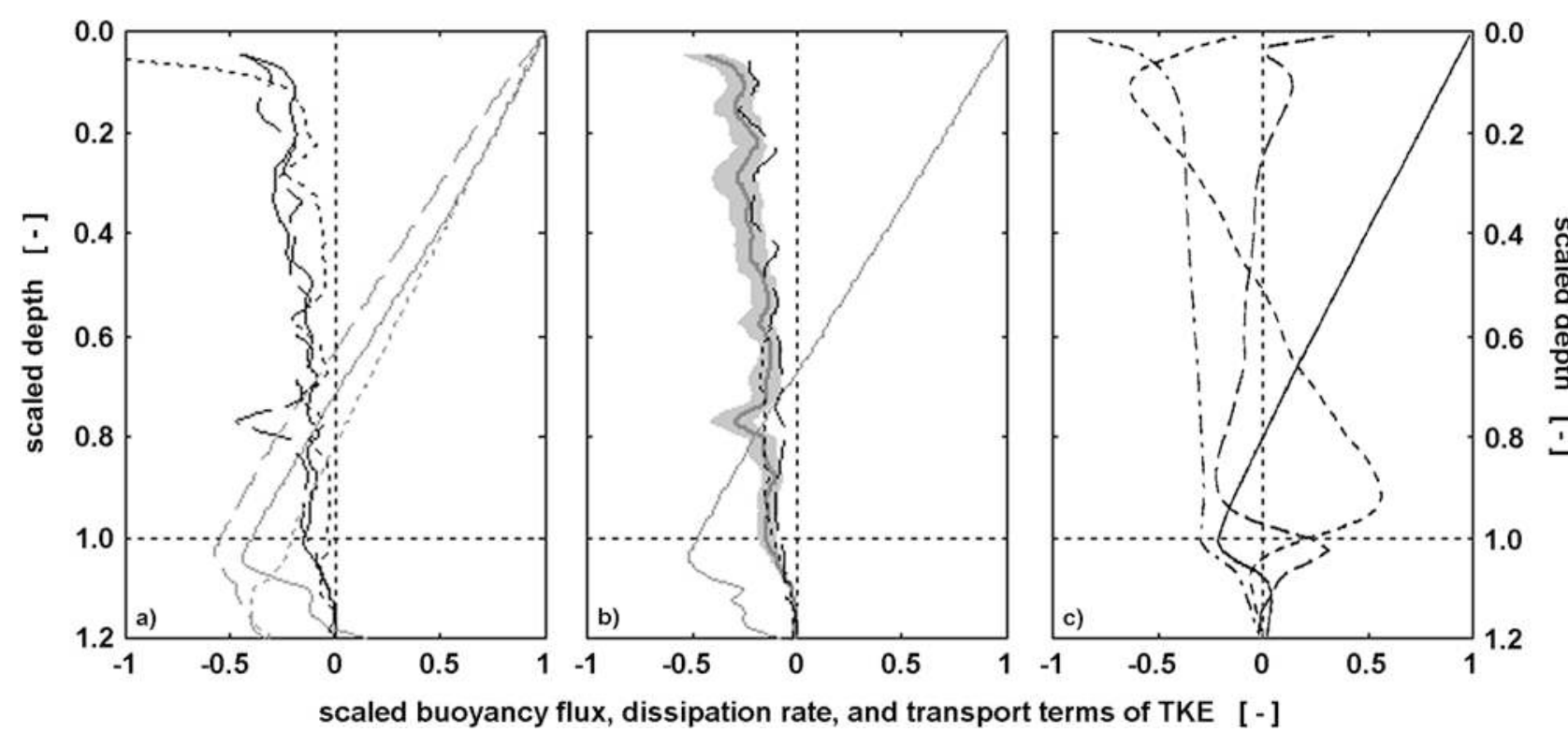

Figure 10. TKE budget terms, scaled with $J_{b}^{0}$ in terms of scaled depth $z / D^{*}$ : (a) averaged profiles for periods of equilibrium stage convection as demarked in Figure 5, of $\varepsilon_{M L E}$ for period i (black solid line), of $\varepsilon_{M L E}$ for period ii (black long-dashed line), of $\varepsilon_{M L E}$ for period iii (black short-dashed line), of $J_{b}$ for period i (gray solid line), of $J_{b}$ for period ii (gray long-dashed line), and of $J_{b}$ for period iii (gray short-dashed line); (b) averaged profiles for periods $i$ and ii of equilibrium stage convection as demarked in Figure 5, of $\varepsilon_{M L E}$ (dark gray solid line) with lower and upper fitting boundaries (gray buffer area), of $\varepsilon_{E A W A G}$ (black long-dashed line), of $\varepsilon_{A D C P}$ (black short-dashed line), and of $J_{b}$ (light gray solid line); (c) profiles adopted from a corresponding LES study by Mironov et al. [2000, Figure 11a], buoyancy flux $J_{b}$ (solid line), dissipation rate of TKE (dot-dashed line), turbulent transport of TKE (short-dashed line), and pressure transport of TKE (long-dashed line).

over depth (i.e., averaging over the $\mathrm{CBL}$ including the entrainment zone in the upper thermocline, $0<z / D^{*}$ $<\approx 1.2$ ), a simple budget between $\varepsilon$ and $J_{b}$ remains, as the transport terms sum up to zero.

[44] An empirical access to the buoyancy flux is given by an approximate parameterization of the transfer equation of heat,

$$
\frac{\partial T}{\partial t}=-\frac{\partial Q_{T}}{\partial z}+\kappa_{T} \frac{\partial^{2} T}{\partial z^{2}}
$$

where $Q_{T}$ is the vertical turbulent temperature flux, and $g \alpha Q_{T}$ is the buoyancy flux. $J_{b}$ can be obtained from multiplying equation (8) with $g \alpha$ and integrating the resulting equation from $z^{\prime}=0$ to $z$,

$$
J_{b}(z)=J_{b}^{0}-g \alpha \int_{0}^{z} \frac{\partial T}{\partial t} d z^{\prime}-\kappa_{T} g \alpha \int_{0}^{z} \frac{\partial^{2} T}{\partial z^{\prime 2}} d z^{\prime},
$$

where $J_{b}^{0}$ is available from the surface heat flux estimates. Note that equation (9) is highly sensitive to seichinginduced displacements of the thermocline. Therefore the estimation of $J_{b}(z)$ below $D^{*}$ can only be a rough approximation.

[45] The buoyant production rate $J_{b}$ and the dissipation rate estimates $\varepsilon_{M L E}, \varepsilon_{E A W A G}$, and $\varepsilon_{A D C P}$ of TKE have been temporally averaged for periods of equilibrium stage convection as demarked in Figure 5. The average profiles are compiled with corresponding results from the above mentioned LES studies in Figure 10. Observational and LES data feature a similar qualitative pattern. TKE is generated only in the top $60-80 \%$ of the CBL. Below, entrainment in the stratified lower bulk of the CBL as well as in the upper thermocline contributes to the increase of potential energy and results in buoyant destruction of TKE [e.g., Deardorff et al., 1969]. Thus for both, the empirical data as well as the LES data, the mean buoyant production rate $J_{b}$ of TKE falls considerably below half the surface buoyancy flux, balancing the respective dissipation rate $\varepsilon$ of TKE. For a quantitative comparison, the average profiles shown in Figure 10 have been integrated over scaled depth $\zeta=z / D^{*}$ down into the interior of the thermocline $\zeta=1.2$ (Table 2), where $\varepsilon$ and $J_{b}$ are assumed to be approximately zero. Our observational data display considerably lower production and dissipation rates of TKE than in respective LES. This finding is attributed to the special set up of the CBL observed at Soppensee. Buoyant plumes entraining cold surface water into the lower bulk of the CBL lead to a buoyant destruction of TKE over significant parts of the $\mathrm{CBL}$ as they run through stable stratification.

\section{Conclusions}

[46] Convection due to surface cooling has been investigated in the surface boundary layer of a small, windprotected lake. Consecutive temperature profiles revealed a stratification pattern considerably different from a classical mixed layer. Beneath a thin super-adiabatic surface layer of approximately $50 \mathrm{~cm}$ thickness, the average stratification 
was found to constantly increase from neutral to $N^{2}=3 \times$ $10^{-5} \mathrm{~s}^{-2}$ toward the base of the convective boundary layer (CBL). This stratification pattern persisted in spite of intense cooling of the entire CBL.

[47] Several mechanisms were considered to allow an active stabilization of the lower bulk of the CBL. Conductivity-temperature-depth transects showed differential cooling to occur at the edges of the lake. However, subsequent horizontal exchange flows were identified as decaying within the first $70 \mathrm{~m}$ from the shore. Also, other lake-scale horizontal heat fluxes could be excluded. Moreover, heat fluxes across or at the expense of the thermocline were quantified as too small to cause the observed stratification. Therefore we conclude that intrusions of cold water from the super-adiabatic surface sublayer account for the active stabilization of the lower bulk of the CBL. This, in particular, involves strong downward plumes that feature a relatively low entrainment rate in the center of the convective layer.

[48] Acoustic Doppler current profiler (ADCP) measurements reveal an asymmetric histogram of vertical velocities. While downward plumes generally featured higher velocities (typically 3-6 $\mathrm{mm} \mathrm{s}^{-1}$ ) than upward plumes (typically 2$3 \mathrm{~mm} \mathrm{~s}^{-1}$ ), they also displayed a more confined plume pattern in contrast to the less canalized upflow. Corresponding large-eddy simulation (LES) studies of convective boundary layers suggest similar flow patterns. Moreover, these studies provide evidence of a reduced entrainment rate in the center bulk of the convective layer. Supporting this finding, we found a characteristic temporal structure of the temperature in the thermistor string record.

[49] The dissipation rate of turbulent kinetic energy (TKE) was estimated on the basis of consecutive temperature microstructure profiles, and from the ADCP data. The dissipation followed the diurnal stratification dynamics, with considerable levels throughout the CBL and in the entrainment zone below. In contrast to other studies on convection under similar conditions, dissipation rates of only about $20 \%$ of the surface buoyancy flux were typically found. However, respectively low buoyancy fluxes (buoyant production rate of TKE) were derived from series of temperature profiles, excellently balancing the observed dissipation rates. We suggest strong convective plumes penetrating through the stable stratification in the lower bulk of the CBL into the thermocline to account for these reduced rates.

[50] Acknowledgments. We would like to thank M. Schurter, H. Prandke, G. Goudsmit, F. Wolk, C. Bolding, T. Ravens and many other colleagues from the participating parties for their effort in connection to the field campaign, C. Schär, J. Sander and our reviewers for critically commenting the manuscript, and D. McGinnis and M. Stubbs for linguistic advice. B. Ruddick kindly provided his software for analyzing temperature microstructure data, as presented by Ruddick et al. [2000]. This study was supported by the Swiss National Science Foundation, grants 20-50761.97 and 2000-063723.00, by the EU Commission, grant MAS3-CT97-0114, and by a Hans-Sigrist Fellowship from the University of Bern.

\section{References}

Anis, A., and J. N. Moum, The superadiabatic surface layer of the ocean during convection, J. Phys. Oceanogr., 22, 1221-1227, 1992.

Anis, A., and J. N. Moum, Prescription for heat flux and entrainment rates in the upper ocean during convection, J. Phys. Oceanogr., 24, $2142-$ 2155,1994

Anis, A., and J. N. Moum, Surface wave-turbulence interactions: Scaling $\varepsilon(z)$ near the sea surface, J. Phys. Oceanogr., 25, 2025-2045, 1995.
Batchelor, G. K., Small-scale variations of convected quantities like temperature in turbulent fluid. part I: General discussion and the case of small conductivity, J. Fluid Mech., 5, 113-133, 1959.

Brainerd, K. E., and M. C. Gregg, Surface mixed and mixing layer depths, Deep Sea Res., Part I, 42, 1521-1543, 1995.

Brainerd, K. E., and M. C. Gregg, Turbulence and stratification on the Tropical Ocean-Global Atmosphere-Coupled Ocean-Atmosphere Response Experiment microstructure pilot cruise, J. Geophys. Res., 102, 10,437-10,455, 1997.

Brubaker, J. M., Similarity structure in the convective boundary layer of a lake, Nature, 330, 742-745, 1987.

Carter, G. D., and J. Imberger, Vertically rising microstructure profiler, J. Atmos. Oceanic Technol., 3, 462-471, 1986.

Deardorff, J. W., Convective velocity and temperature scales for the unstable planetary boundary layer and for Raleigh convection, J. Atmos. Sci., 27, 1211-1213, 1970 .

Deardorff, J. W., and G. E. Willis, Dependence of mixed-layer entrainment on shear stress and velocity jump, J. Fluid Mech., 115, 123-149, 1982.

Deardorff, J. W., G. E. Willis, and D. K. Lilly, Laboratory investigation of non-steady penetrative convection, J. Fluid Mech., 35, 7-31, 1969.

Dillon, T. M., and D. R. Caldwell, The Batchelor spectrum and dissipation in the upper ocean, J. Geophys. Res., 85, 1910-1916, 1980.

Eugster, W., G. Kling, T. Jonas, J. P. McFadden, A. Wüest, S. MacIntyre, and F. S. Chapin III, $\mathrm{CO}_{2}$ exchange between air and water in an Arctic Alaskan and mid-latitude Swiss lake: Importance of convective mixing, J. Geophys. Res., 108(D12), 4362, doi:10.1029/2002JD002653, 2003.

Fer, I., U. Lemmin, and S. A. Thorpe, Observations of mixing near the sides of a deep lake in winter, Limnol. Oceanogr., 47, 535-544, 2002.

Gargett, A. E., T. R. Osborn, and P. W. Nasmyth, Local isotropy and the decay of turbulence in a stratified fluid, J. Fluid Mech., 144, 231-280, 1984.

Gibson, C. H., and W. H. Schwartz, The universal equilibrium spectra of turbulent velocity and scalar fields, J. Fluid Mech., 16, 365-384, 1963.

Gloor, M., Methode der Temperaturmikrostruktur und deren Anwendung auf die Bodengrenzschicht in geschichteten Wasserkörpern, Ph.D. thesis, Eidg. Tech. Hochschule, Zürich, Switzerland, 1995.

Gordon, L., A. Lohrmann, and T. Jonas, Internal wave generation in lakes with very slow flow, paper presented at IEEE 6th Working Conference on Current Measurement, Inst. Electr. and Electr. Eng., San Diego, Calif., 1999.

Grant, H. L., R. W. Stewart, and A. Moilliet, Turbulent spectra from a tidal channel, J. Fluid Mech., 12, 241-268, 1962.

Grant, H. L., B. A. Hughes, M. W. Vogel, and A. Moilliet, The spectrum of temperature fluctuations in turbulent flow, J. Fluid. Mech., 34, 423-442, 1968.

Gregg, M. C., C. S. Cox, and P. W. Hacker, Vertical microstructure measurements in the central North Pacific, J. Geophys. Res., 3, 458-469, 1973.

Guillemet, B., H. Isaka, and P. Mascart, Molecular dissipation of turbulent fluctuations in the convective mixed layer. part I: Height variations of dissipation rates, Boundary Layer Meteorol., 27, 141-162, 1983.

Haine, T. W. N., and J. Marshall, Gravitational, symmetric, and baroclinic instability of the ocean mixed layer, J. Phys. Oceanogr., 28, 634-658, 1998.

Hinze, J. O., Turbulence, 2nd ed., 790 pp., McGraw-Hill, New York, 1975. Horsch, G. M., and H. G. Stefan, Convective circulation in littoral water due to surface cooling, Limnol. Oceanogr., 33, 1068-1083, 1988.

Imberger, J., The diurnal mixed layer, Limnol. Oceanogr., 30, 737-770, 1985.

Jonas, T., Convective mixing processes in natural waters, Ph.D. thesis, Eidg. Tech. Hochschule, Zürich, Switzerland, 2001.

Jones, E. P., and S. D. Smith, A first measurement of sea-air $\mathrm{CO}_{2}$ flux by eddy correlation, J. Geophys. Res., 82, 5990-5992, 1977.

Kaimal, J. C., J. C. Wyngaard, D. A. Haugen, O. R. Coté, and Y. Izumi, Turbulence structure in the convective boundary layer, J. Atmos. Sci., 33, 2152-2169, 1976.

Kocsis, O., H. Prandke, A. Stips, A. Simon, and A. Wüest, Comparison of dissipation of turbulent kinetic energy determined from shear and temperature microstructure, J. Mar. Syst., 21, 67-84, 1999.

Kolmogorov, A. N., Local turbulence structure in incompressible fluids at very high Reynolds number, C. R. Hebd. Seances Acad. Sci., 30, 299303,1941 .

Lenschow, D. H., J. C. Wyngaard, and W. T. Pennell, Mean-field and second-moment budgets in a baroclinic, convective boundary layer, J. Atmos. Sci., 37, 1313-1326, 1980.

Lombardo, C. P., and M. C. Gregg, Similarity scaling of viscous and thermal dissipation in a convecting surface boundary layer, J. Geophys. Res., 94, 6273-6284, 1989.

Luketina, D. A., and J. Imberger, Determining turbulent kinetic energy dissipation from Batchelor curve fitting, J. Atmos. Oceanic Technol., 18, 100-113, 2001. 
Mahrt, L., and J.-C. André, On the stratification of turbulent mixed layers, J. Geophys. Res., 88, 2662-2666, 1983.

Marshall, J., and F. Schott, Open-ocean convection: Observations, theory and models, Rev. Geophys., 37, 1-64, 1999.

Mason, P. J., Large-eddy simulation of the convective atmospheric boundary layer, J. Atmos. Sci., 46, 1492-1516, 1989.

Mironov, D. V., V. M. Gryanik, C.-H. Moeng, D. J. Olbers, and T. H. Warncke, Vertical turbulence structure and second-moment budgets in convection with rotation: A large-eddy simulation study, Q.J.R. Meteorol. Soc., 126, 477-515, 2000.

Monismith, S. G., J. Imberger, and M. L. Morison, Convective motion in the sidearm of a small reservoir, Limnol. Oceanogr., 35, 1676-1702, 1990.

Mudge, T. D., and R. G. Lueck, Digital signal processing to enhance oceanographic observations, J. Atmos. Oceanic Technol., 11, 825-836, 1994.

Noh, Y., and H. J. Kim, Simulations of temperature and turbulence structure of the oceanic boundary layer with the improved near-surface process, J. Geophys. Res., 104, 15,621-15,634, 1999.

Oakey, N. S., Determination of the rate of dissipation of turbulent energy from simultaneous temperature and velocity shear microstructure measurements, J. Phys. Oceanogr., 12, 256-271, 1982.

Peters, H., M. C. Gregg, and J. M. Toole, On the parameterization of equatorial turbulence, J. Geophys. Res., 93, 1199-1218, 1988.

Priestley, M. B., Spectral Analysis and Time Series, Academic, San Diego, Calif., 1981.

Ruddick, B., A. Anis, and K. Thompson, Maximum likelihood spectral fitting: The Batchelor spectrum, J. Atmos. Oceanic Technol., 17, 15411555,2000

Sander, J., A. Simon, T. Jonas, and A. Wüest, Surface turbulence in natural waters: A comparison of large eddy simulations with microstructure observations, J. Geophys. Res., 105, 1195-1207, 2000.

Shay, T. J., and M. C. Gregg, Turbulence in an oceanic convecting mixed layer, Nature, 310, 282-285, 1984.

Shay, T. J., and M. C. Gregg, Convectively driven turbulent mixing in the upper ocean, J. Phys. Oceanogr., 16, 1777-1798, 1986.

Simon, A., Turbulent mixing in the surface boundary layer of lakes, Ph.D. thesis, Eidg. Tech. Hochschule, Zürich, Switzerland, 1997.
Smith, S. D., R. J. Anderson, E. P. Jones, R. L. Desjardins, R. M. Moore, O. Hertzman, and B. D. Johnson, A new measurement of $\mathrm{CO}_{2}$ eddy flux in the nearshore atmospheric surface layer, J. Geophys. Res., 96, $8881-8887,1991$.

Soloviev, A. V., and P. Schlüssel, Evolution of cool skin and direct air-sea gas transfer coefficient during daytime, Boundary Layer Meteorol., 77, 45-68, 1996.

Sturman, J. J., C. E. Oldham, and G. N. Ivey, Steady convective exchange flows down slopes, Aquat. Sci., 61, 260-278, 1999.

Taylor, G. I., The spectrum of turbulence, Proc. R. Soc. London, Ser. A, 164, 476-490, 1938.

Tennekes, H., and J. L. Lumley, A First Course in Turbulence, MIT Press, Cambridge, Mass., 1972.

Thorpe, S. A., Experiments on the stability of stratified shear flows, Radio Sci., 4, 1327-1332, 1969.

Thorpe, S. A., U. Lemmin, C. Perrinjaquet, and I. Fer, Observations of the thermal structure of a lake using a submarine, Limnol. Oceanogr., 44, $1575-1582,1999$.

Wyngaard, J. C., and O. R. Coté, The budget of turbulent kinetic energy and temperature variance in the atmosphere surface layer, J. Atmos. Sci., 28, 190-201, 1971

Yaglom, A. M., Laws of small-scale turbulence in the atmosphere and in the ocean, Izv. Russ. Acad. Sci. Atmos. Oceanic Phys., Engl. Transl., 17, 919-935, 1981.

W. Eugster, Geographical Institute, University of Bern, Hallerstrasse 12, CH-3012 Bern, Switzerland. (eugster@giub.unibe.ch)

T. Jonas, Alpine Environment Section, Swiss Federal Institute for Snow and Avalanche Research, Flüelastrasse 11, CH-7260 Davos Dorf, Switzerland. (jonas@slf.ch)

A. Stips, Inland and Marine Waters Unit, CEC Joint Research Centre, TP 272, I-21020 Ispra, Italy. (adolf.stips@jrc.it)

A. Wüest, Applied Aquatic Ecology, Limnological Research Center Kastanienbaum, EAWAG, Seestrasse 79, CH-6047 Kastanienbaum, Switzerland. (wuest@eawag.ch) 